\title{
Examining rhythmic and metric practices in Led Zeppelin's musical style
}

\author{
JOHN BRACKETT
}

University of Utah, 1375 E. Presidents Circle, Salt Lake City, UT 84112-0030, USA

E-mail: john.brackett@utah.edu

\begin{abstract}
In this essay, I examine how aspects of rhythm and metre play a fundamental role in shaping and defining Led Zeppelin's musical style. At the same time, I will show how Led Zeppelin was able to modify, manipulate, and develop pre-existing musical models and forms through various rhythmic and metric strategies. Comparative analyses will be used in an effort to show how Led Zeppelin's flexible conception of rhythm and metre enabled the band to put their own stylistic 'stamp' on (i) specific musical genres ('The Crunge' and the song's relation to James Brown-style funk), (ii) their riff constructions ('Black Dog' in relation to Fleetwood Mac's 'Oh Well'), and (iii) their cover versions ('Dazed and Confused'). Drawing upon my analytical points, I re-visit the complex issues that persist regarding the possibility that Led Zeppelin even has an 'original' or 'unique' style given their often overt reliance upon earlier musical models and forms. Therefore, in my conclusion, I argue that the development of any artist or group's individual style necessarily involves the ability to assimilate and transform pre-existing musical features features such as rhythm and metre - in novel ways and where issues relating to musical style intersect with influence.
\end{abstract}

\section{Introduction}

Led Zeppelin's distinctive approach to matters relating to rhythm and metre is often identified as a key feature of the band's individual style. For example, in a published conversation between Andrew Goodwin and Joe Gore, Goodwin describes how 'funky [the band's sound] is', a feature Gore attributes to drummer John Bonham's 'slower, lazier, slightly behind-the-beat feel that's different from the lockstep, straight up-and-down feel of most other heavy rock like Deep Purple or the Scorpions. There's more of a tension. A slight tease about where the beat is placed'. Focusing on particular songs, Gore notes that on "Black Dog", which is usually perceived as a straightforward rock number, the meter is unusual. But John Bonham plays it absolutely straight, setting up a tension that's technically quite complex for rock, but which sounds very funky ...'. On the pervasive use of odd-time signatures in songs such as 'The Crunge', 'The Ocean' and 'Over the Hills and Far Away', Goodwin suggests that 'the measure of success here is how little attention it draws to itself ... you groove to it, it's not like hearing a King Crimson or Genesis song where it holds up a flag and congratulates itself [on its metric complexity]' (Goodwin and Gore 1987, pp. 6-7). 


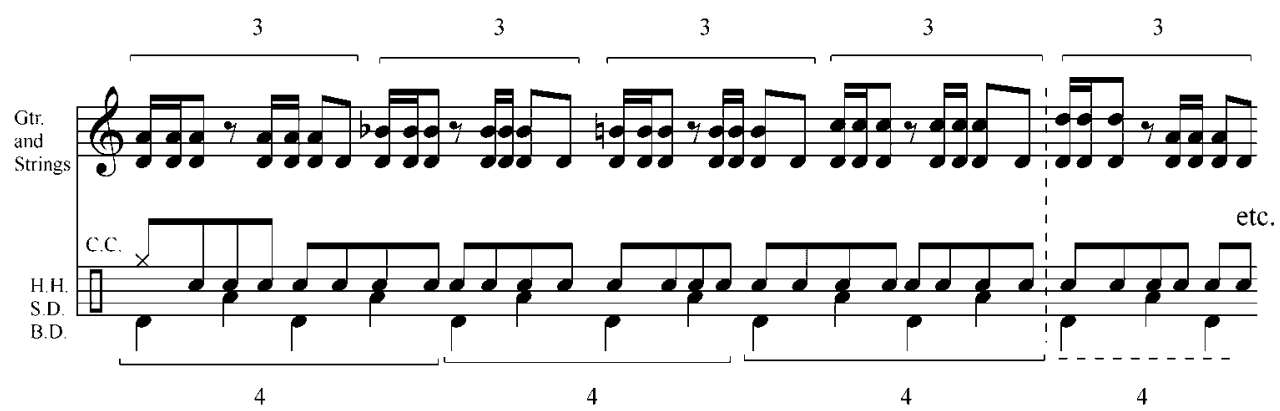

Example 1. Superimposition of 3 and 4 groupings in 'Kashmir'.

While Goodwin and Gore can both be accused of overstating the imperceptibility of such metric phenomena, they do have a point regarding a key component of the band's individual style. In an interview from 1972, Robert Plant, the band's lead singer, authenticates these opinions. In this interview, Plant emphasises the band's interest in matters relating to musical time:

Interviewer: When you first got the band together, you must have had some basic ideas, [some] basic musical concepts as a group that you wanted to follow. How would you sum those up?

Robert Plant: Well, at the beginning it was the construction of things with different time patterns and with changes ... y'know like in 'Dazed and Confused' and 'How Many More Times?' which somehow or another came to us like that [snaps his fingers]. Y'know everybody just skipped in and fell in ... very seldom did [the music] sort of ease its way into another change it just fell automatically, $\mathrm{y}^{\prime}$ know. So that was the first thing we got into ... ${ }^{1}$

The band's interest in musical time was not restricted to their early records. Two familiar examples will illustrate the continued importance played by 'different time patterns' and 'time changes' (i.e. explorations of a variety of rhythmic and metric possibilities) in Led Zeppelin's later music.

'Kashmir', from the band's Physical Graffiti record, is notable for the superimposition of two groupings - groupings of three in the string and guitar parts and groupings of four in John Bonham's drumset part, shown in Example 1 (see also Moore 1993, p. 71; Fast 2001, chap. 3). These layers pull back and forth against each other creating a tension that is momentarily resolved when the two layers line up, shown by the dotted line that extends through both staves near the end of Example 1. On the one hand, it is possible that these superimpositions form the 'hook' of the song. That is, as listeners, we are constantly engaged by the continuously shifting parts and their eventual alignment. On the other hand, it can also be argued that the listener is never forced to decide between a single metric interpretation of these groupings - say, the $3 / 4$ of the guitar and string layer or the $4 / 4$ of the drum layer. Instead, we are carried along by the song's overall rhythmic flow and tend to focus only on the points of coincidence; how we get to these points is of no concern to us. Robert Plant's vocal part adds to this feeling as he seems to sing in a manner that is completely independent of these metric incongruities.

A second example, 'Custard Pie' also from Physical Grafitti, opens with Jimmy Page's solo guitar playing the primary riff, repeated four times. ${ }^{2}$ I would argue that we begin to form some sort of metric context at some point shortly after the onset of the second repetition and, by the third repetition we have probably 'settled' in to, or decided upon, some type of metric regularity. Example $2 \mathrm{a}$ represents one way of 

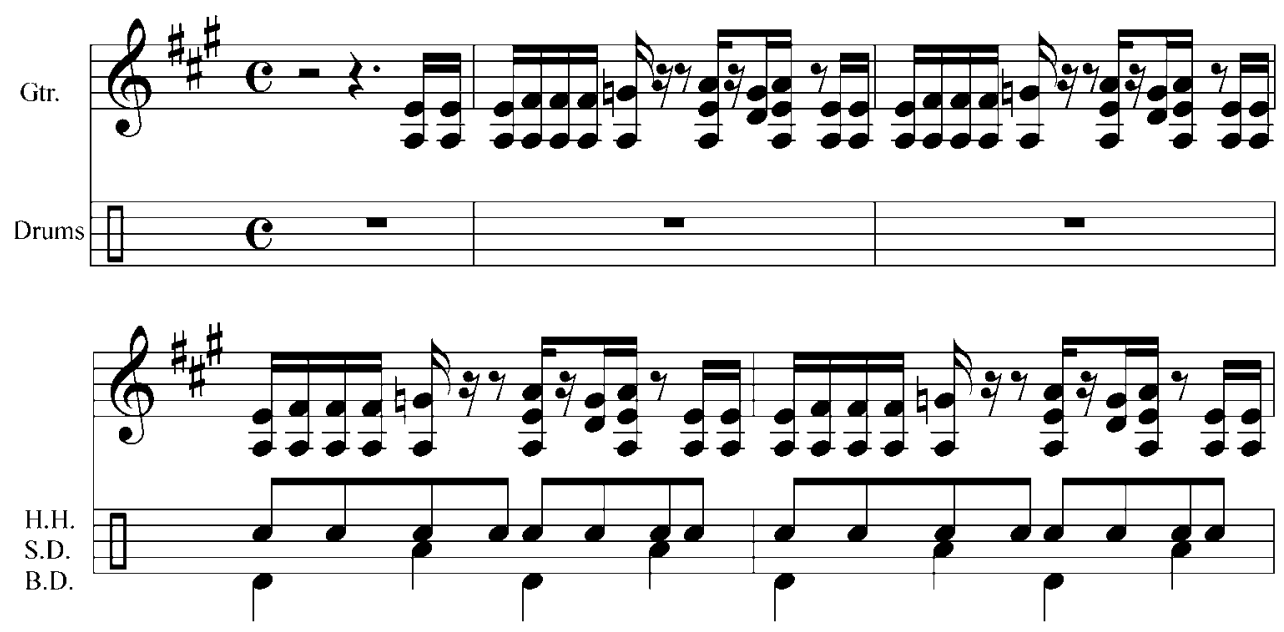

Example 2a. Possible metric interpretation of 'Custard Pie'.

hearing metre at the song's opening. Here, the riff begins as an anacrusis to a suppressed (deliberately unaccented) downbeat. If we hear the riff this way, we can imagine the drumset pattern that enters in measure 4 of Example 2a. Here, the first snare drum articulation is coordinated with the end of a subphrase within the riff (the arrival on the pitch $\mathrm{G}$ as part of the $\mathrm{E}-\mathrm{F} \#-\mathrm{G}$ ascent in the top part of the guitar line). The next snare drum attack (on beat 4) fills in the space between the end of the riff and its repetition. While this might be a perfectly acceptable way of hearing some type of metric structure for the opening unaccompanied guitar riff, it is not realised. With the actual drum entrance, the opening of the riff coincides with a downbeat as shown in Example $2 \mathrm{~b}$. In this example, notice that drummer John Bonham appears to acknowledge the type of hearing represented in Example 2a. The first snare drum attack in every measure occurs on the 'and' of beat 2 corresponding with the end of the riff's first subphrase (the conclusion of the E-F\#-G ascent). At the same time, Bonham's syncopated bass drum part emphasises the ascending pitch line in the guitar (the same $\mathrm{E}-\mathrm{F} \#-\mathrm{G}$ figure). With the entrance of the complete drumset, therefore, the metric positioning of the riff is clarified. ${ }^{3}$

Both 'Kashmir' and 'Custard Pie' are original songs and both evince certain rhythmic/metric 'interplays and subtleties' (Moore 1993, p. 71) common to much of Led Zeppelin's music. It is clear that the band devoted as much attention to these musical parameters as they did to their riff constructions, formal structures, and recorded sound. In this essay, I will examine how aspects of rhythm and metre play a fundamental role in shaping and defining Led Zeppelin's musical style. At the same time, I will show how Led Zeppelin was able to modify, manipulate and develop pre-existing musical models and forms through various rhythmic and metric strategies. Comparative analyses will be used in an effort to show how Led Zeppelin's flexible conception of rhythm and metre enabled the band to put their own stylistic 'stamp' on (i) specific musical genres ('The Crunge' and the song's relation to James Brown-style funk), (ii) their riff constructions ('Black Dog' in relation to Fleetwood Mac's 'Oh Well'), and (iii) their cover versions ('Dazed and Confused').

In many ways, my examination of the rhythmic and metric aspects of Led Zeppelin's style continues and develops the methodology employed in Headlam 

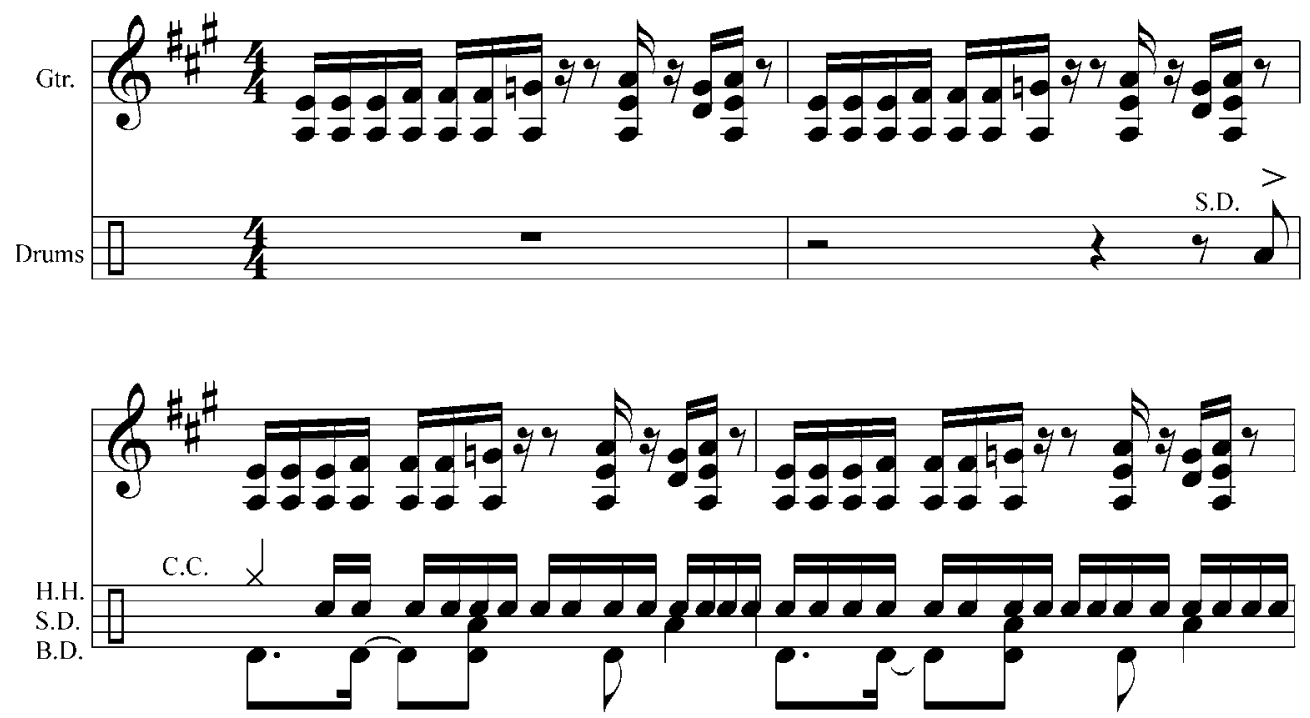

Example 2b. Realised melodic/metric structure of 'Custard Pie'.

(1995). Whereas Headlam focuses specifically on the relations and transformations between earlier songs and Led Zeppelin's 'cover versions', I hope to broaden this area of investigation by considering how Led Zeppelin not only transforms specific songs (in the case of 'Dazed and Confused' which, as we will see, can be understood as a 'cover of a cover') but also musical genres and other musical models as well. Following this line of thought, we are forced to re-visit the complex issues that persist regarding the possibility that Led Zeppelin even has an 'original' or 'unique' individual style given their reliance upon earlier musical models and forms. Therefore, in my conclusion, I will briefly consider the notions of influence and originality and how they figure into discussions of musical style.

\section{'The Crunge'}

'The Crunge', from the band's fifth album Houses of the Holy, is, quite clearly, Led Zeppelin's attempt at James Brown-style funk, complete with Robert Plant's own take on the recurring request to 'Take me to the bridge' as heard in Brown's 'Sex Machine', 'Mother Popcorn', 'In A Cold Sweat', and many others. In the case of 'The Crunge', the joke is that the song has no bridge: Plant wonders 'Where is the bridge?' and 'Has anyone seen the bridge?' The funk parody heard in 'The Crunge' also extends to the song's rhythmic and metric organisation. We may expect a funk song to establish some sort of 'groove' that, although highly syncopated on the musical surface, is metrically unambiguous. This is not the case with 'The Crunge' where metric irregularities dominate the song creating - what Chris Welch calls - a 'dance groove that you [can't] dance to' (Welch 1999, p. 80).

In his analysis of James Brown's 'Superbad', David Brackett describes a number of musical features that are common to a great many funk songs (Brackett 1995, chap. 4). Building on Wilson (1974), Brackett points to certain timbral regularities, specifically the 'intensification of the musical lines by means of emphasising the independence of timbre (color) for each voice' as well as the 'high density of musical 


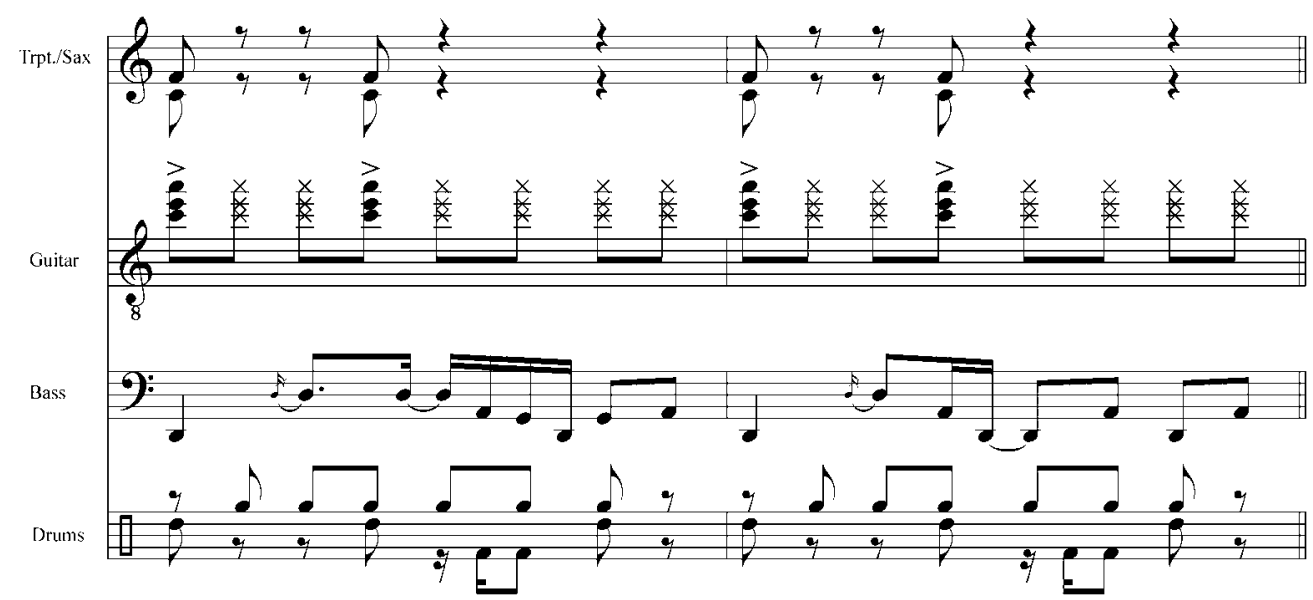

Example 3. Texture X from James Brown's 'Superbad' (Brackett 1995, Example 4.3, p. 141).

events within a relatively short musical space'. Wilson writes that there 'tends to be a profusion of musical activities going on simultaneously, as if an attempt is being made to fill up every available area of musical space' (Wilson 1974, pp. 15-16; Brackett 1995, p. 136). Brackett develops Wilson's analysis by considering how aspects of metre and rhythm figure in various textures heard throughout the song. Here, the distinct rhythmic and metric profiles of the independent musical lines 'emphasize how the different accentual patterns create a complex, compelling "groove" ...' (Brackett 1995, p. 139). ${ }^{4}$ Example 3 reproduces Texture X from Brackett's Example $4 \cdot 3$. This example can be understood as a generic textural and rhythmic representation of a great many funk songs. The short, choked bursts in the horns and guitar emphasise the first half of each measure leaving the bass guitar's busy sixteenth-note figuration to complete the rest of the measure while, at the same time, providing a driving pulse leading into the next measure. All of the instrumental layers emphasise the downbeat, even the snare drum. This is exceptional, perhaps, given the predominance of the back-beat pattern common in so much popular music where the snare drum emphasises beats 2 and $4 .{ }^{5}$ We can consider Brackett's Texture X from Brown's 'Superbad' as a textural and rhythmic/metric model commonly found in many of Brown's funk tunes. Of course there will always be variations and modifications but many of the features we generally associate with James Brown-style funk are present: independent musical lines with characteristic timbral associations, complex rhythmic interactions, and, most important for my discussion, a continuous and unambiguous metric 'groove'.

Jimmy Page, guitarist for Led Zeppelin, has commented upon the band's interest in funk music. In particular, Page mentions the influence of funk on 'The Crunge': " "The Crunge" just happened spontaneously. Bonzo [drummer John Bonham] started playing, Jonesy [bassist John Paul Jones] came in next and then I joined in. It happened as quickly as that. At the time it seemed to be undanceable, because it keeps crossing over from the on to the off beat, as opposed to most James Brown things which are totally danceable' (Kendall and Lewis 1995, pp. 65-6). Interestingly, Led Zeppelin would sometimes incorporate moments of Brown's 'Sex Machine' in live performances. During their performance of 'Whole Lotta Love' from 25 March 1975 in Los Angeles, for example, the band broke into Brown's 'Sex Machine' before leading into 


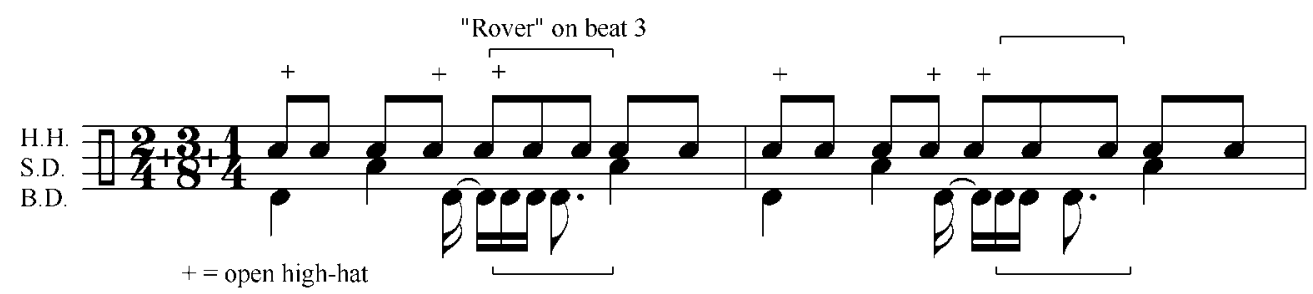

Example 4. 'The Crunge' - drumset opening.

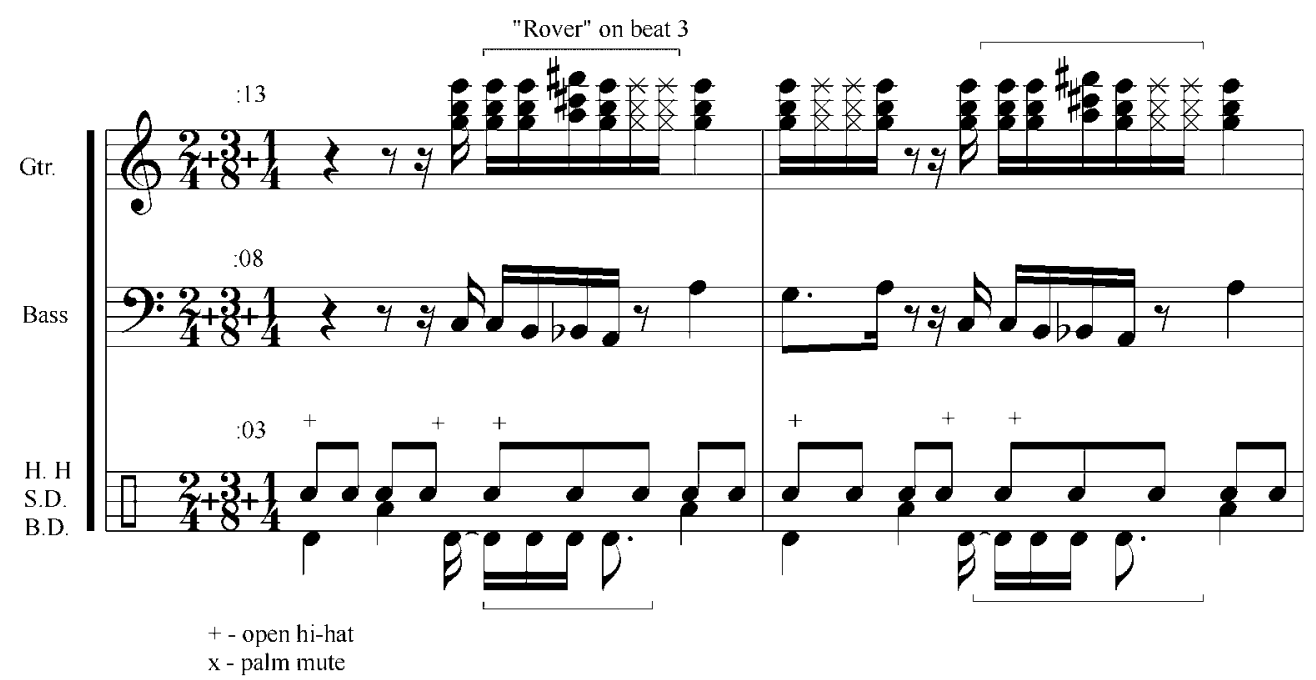

Example 5. 'The Crunge' - opening according to metric structure established by drums.

the psychedelic, 'freak-out' section. Before this, the rhythm section can briefly be heard playing the opening of 'The Crunge'. ${ }^{6}$

The 'undanceable' irregularities of 'The Crunge' are the result of a single elongated beat that embellishes a quadruple metre (Example 4). This one beat comprises three eighth notes and, when combined with the three remaining large beats in each measure, creates, in effect, a measure of nine. ${ }^{7}$ In Example 4, I have highlighted the elongated beat with braces and provided it with a name - 'The Rover'. The song opens with John Bonham laying down the drum groove and, in the absence of any supporting metric context from the rest of the rhythm section, the elongated beat can be heard as occurring on beat 3 , creating some sort of $2 / 4+3 / 8+1 / 4$ metric interpretation. The bass drum part on the elongated beat 3 can be understood as a 'mishearing' or, perhaps, an attempt at replicating the syncopated bass drum part in the same part of the measure in 'Superbad'.

Gradually, the overall texture of 'The Crunge' begins to emerge as the remaining instruments enter. As shown in Example 5, the next instrument to enter is John Paul Jones' bass part (at 00:08). The bass line begins with a quick chromatic descent from $\mathrm{C}$ down to the tonic A followed by an octave leap that is embellished with the lower $b 7$ neighbour-note, G. Referring back to Example 3, we can see how this figure directly parallels the bass part in 'Superbad'. Jimmy Page's rhythm guitar part enters next playing short, choked chords that duplicate the rhythms heard in Jones' bass part, perhaps mimicking the horn and guitar parts of Brown's song. As the other 


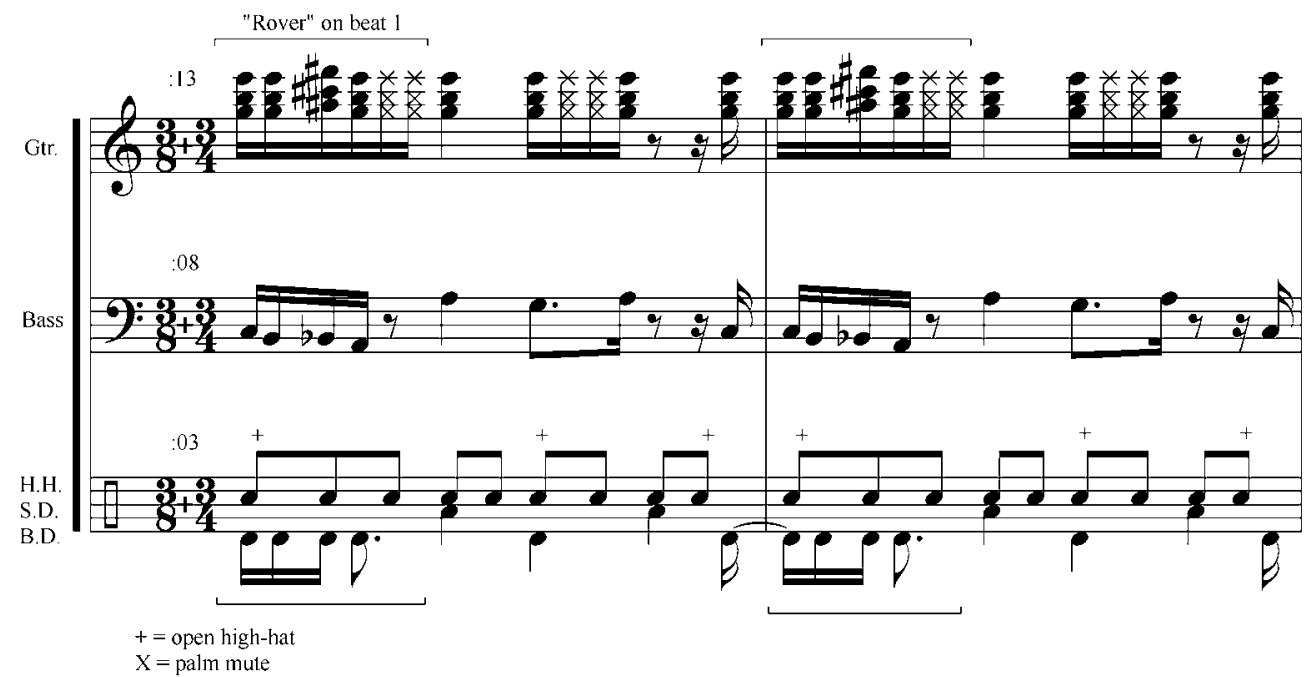

Example 6. 'The Crunge' - revised hearing of metre in opening.

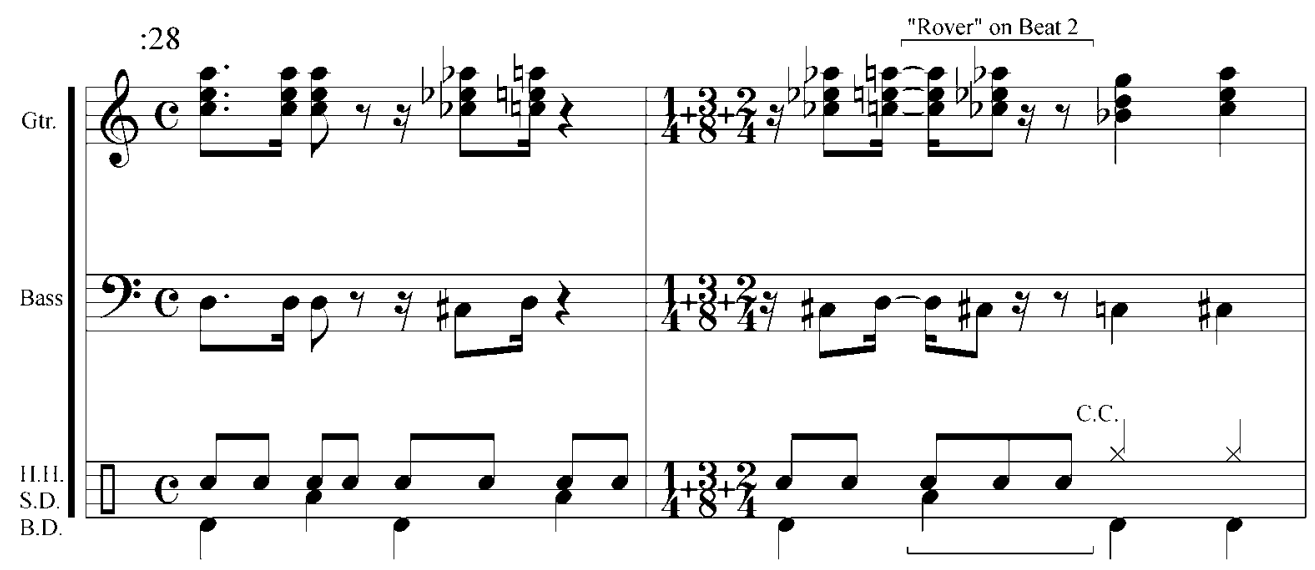

Example 7. 'The Crunge' - return of 'The Rover' in verse.

instruments enter and the Brown-like stratified texture emerges, it is difficult to sustain the melodic and rhythmic phrasings of the bass and guitar parts according to the $2 / 4+3 / 8+1 / 4$ metric structure established by the drums. As can be seen in Example 5, we would need to hear the bass and guitar phrases across the 'mental barline' we have supplied since the beginning of the song. To simplify matters, therefore, it may be best to understand the opening according to a different metric interpretation, possibly one represented by Example 6. Here, the first sixteenth-note in both the bass and guitar parts functions not only as a pick-up to The Rover figure itself, but also as a pick-up to a new measure. This way of hearing transfers The Rover from beat 3 to beat 1 , notated as $3 / 8+3 / 4$.

Although 'The Crunge' might still be difficult to dance to, we seem to know exactly where we would have to make an adjustment in our steps - beat 1 . Unfortunately, The Rover has other ideas. Beginning with the first verse, The Rover figure is heard again but now on beat 2 as seen in the second measure of Example 7. 

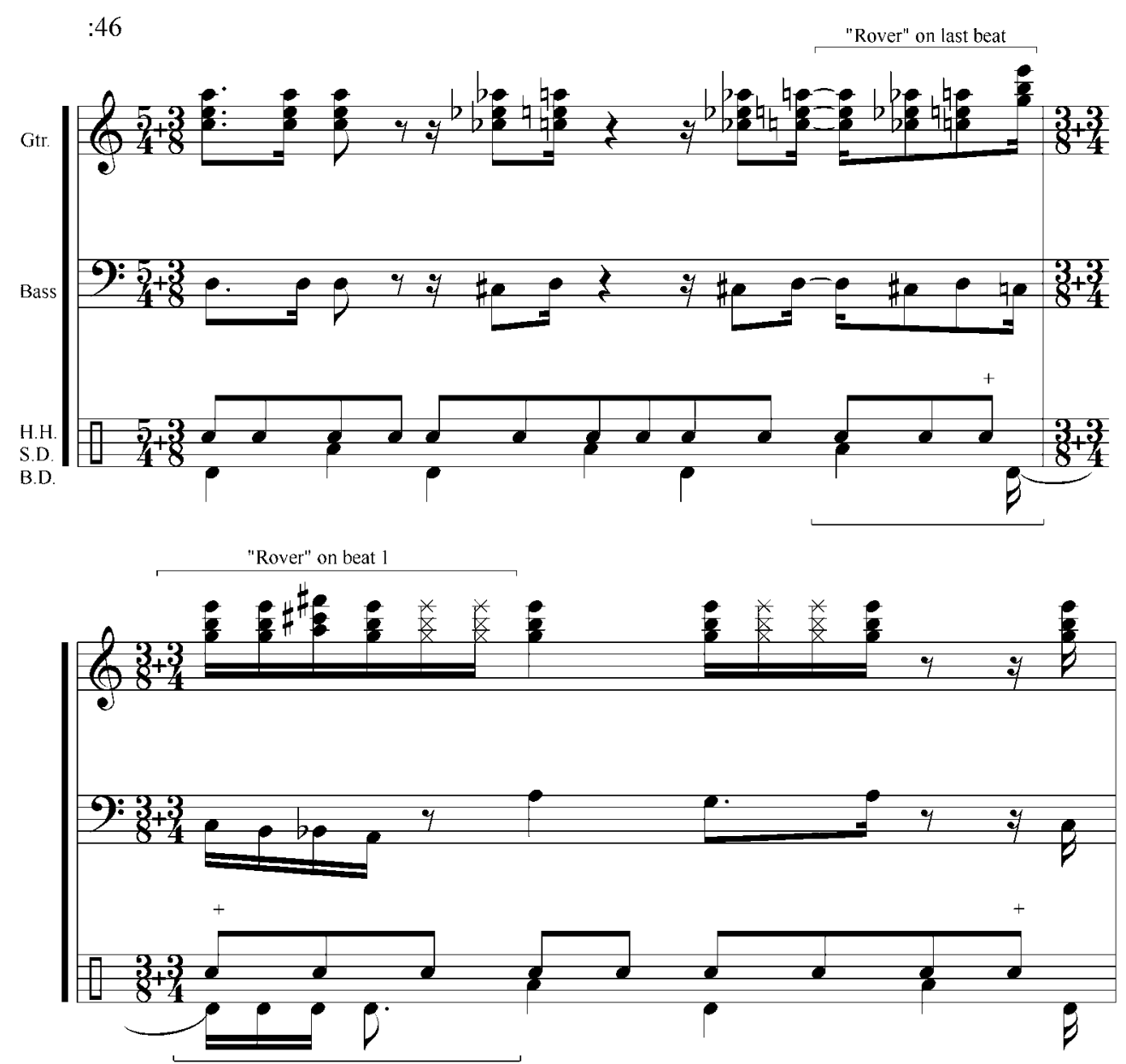

Example 8. 'The Crunge' - 'The Rover' heard in the turnaround from the verse to the riff.

The Rover is not done roving, however, appearing again as a turnaround figure connecting the end of the verse to the return of the riff. As I have transcribed it in Example 8, The Rover is attached at the end of a 'measure' comprised of six beats.

Metrically, The Rover certainly gets around. Throughout the song, we can hear The Rover in four metric positions: beat 3 in the unaccompanied drum opening which is subsequently transferred to beat 1 with the entrance of the guitar and bass parts, beat 2 in the verse, and beat 6 , the last beat at the turnaround from the verse to the return of the riff. Despite the various metric positions occupied by The Rover, the song still exhibits a strong quadruple regularity (except for the turnaround measure). Although we hear the song 'in four', it is a 'limping' four - definitely not a 'funky' four. Certain funk elements, however, are still recognisable: for example, Plant's vocal delivery and lyrics, the stratification of instrumental layers, the choked guitar voicings and active bass line. The thing that makes funk 'funky' - the danceable groove is nowhere to be found. Because of The Rover's metric peregrinations and irregular length, it is, perhaps, not surprising that the band abandoned their original idea for the cover of Houses of the Holy - Fred Astaire-like dance step diagrams showing album buyers how to dance 'The Crunge'. 
Bassist John Paul Jones recalls how he and drummer John Bonham were 'James Brown freaks' and how they would constantly play his records while on tour (Palmer 1990, [n.p.]). 'The Crunge' can be understood as Led Zeppelin's return gift, or an homage, to Brown in particular and funk music in general. While the 'irregular regularities' created by The Rover can create the impression that Led Zeppelin did not entirely 'get' the meaning and essence of funk, it may also be viewed as a stylistic marker signifying Led Zeppelin's style. Instead of trying to recreate the generic template common to a great deal of James Brown-style funk, the inclusion of a mobile, irregular beat in 'The Crunge' represents Zeppelin's contribution to the funk genre.

\section{'Black Dog'}

Whereas Led Zeppelin modified genre expectations in 'The Crunge', they had a more specific model in mind with 'Black Dog' from their fourth album. The riff to 'Black Dog' was composed by bassist John Paul Jones and, as Jimmy Page has mentioned in interviews, was influenced by the riff to Fleetwood Mac's 'Oh Well'. ${ }^{\circ}$ Both songs contain the distinctive call and response form between the solo vocalist who is then answered by the riff. In addition to this formal similarity, a number of notable motivic relations exist between the structure of the riff to 'Oh Well' and the riff to 'Black Dog'. ${ }^{9}$ Comparing Example 9 with the riff to 'Black Dog' (look ahead to Examples 10 and 11), we can see that (i) both begin with an anacrusis figure (highlighted in Example 9 with a solid box); (ii) both end with a long held note directly preceded by a syncopated figure that throws off the established rhythmic and metric regularity (dashed box); (iii) both contain a distinctive ascending chromatic figure (in ovals). Where Led Zeppelin's riff is a single melodic gesture, Fleetwood Mac's riff comprises three distinct units: an opening idea formed by the fast eighth-notes heard in alternation between the acoustic and electric guitars (from the end of the first system to the end of the third), a middle idea played by the electric guitar (fourth system through measure two of the fifth system), and a closing scalar figure where the acoustic guitar briefly returns. The greatest amount of tension is present in this closing idea as syncopation becomes predominant and by the fact that the electric guitar and acoustic guitar reach their harmonic goals at two different times. The goal pitch of $E$ is reached by the electric guitar on the and of beat 2 as the acoustic guitar is playing a $\mathrm{D}$ major triad that does not resolve to $\mathrm{E}$ minor until beat 4 . Our attention is drawn to this spot by the fact that the syncopation is broken at this point: the emphasis on off-beats is prolonged by an eighth-note setting up the 'real' arrival on beat 4 . Even this arrival is bit unsettling as we expect this major formal and structural event to occur on a downbeat. As the guitars sustain their pitches, cowbells and maracas re-establish the pulse leading to the entry of the complete band supporting a guitar solo. The pulse is maintained throughout the held notes while the band's entry on a strong downbeat satisfies, perhaps, any lingering sense of metric ambiguity.

As certain features of the riff to Fleetwood Mac's 'Oh Well' were absorbed into the riff to Led Zeppelin's 'Black Dog', Led Zeppelin adapted these features in a number of important ways. In constructing the riff to 'Black Dog', Led Zeppelin developed the potential rhythmic and metric irregularities nascent in Fleetwood Mac's riff. By doing so, Led Zeppelin were able to transform the riff into something that was stylistically in line with their own group aesthetic, an aesthetic relating to matters of 'time' described by Plant above. 

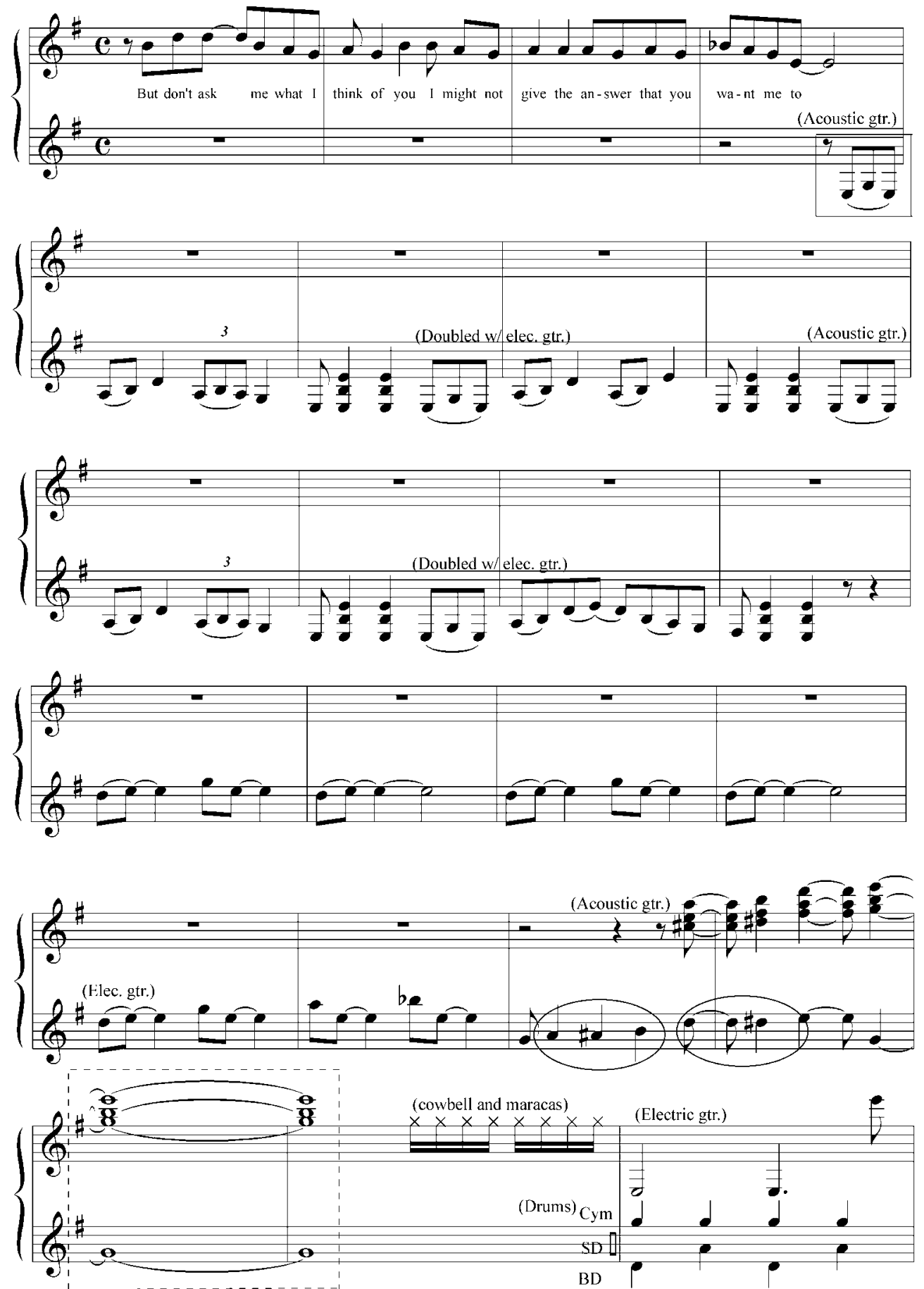

Example 9. 'Oh Well' (Fleetwood Mac) - main riff showing motivic similarities to riff to 'Black Dog'. 


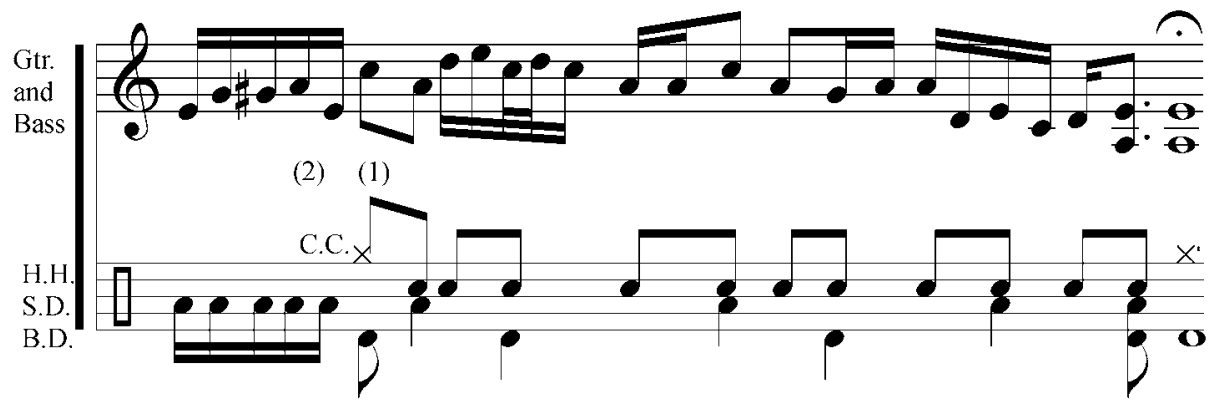

Example 10. 'Black Dog' (studio version) - main riff.

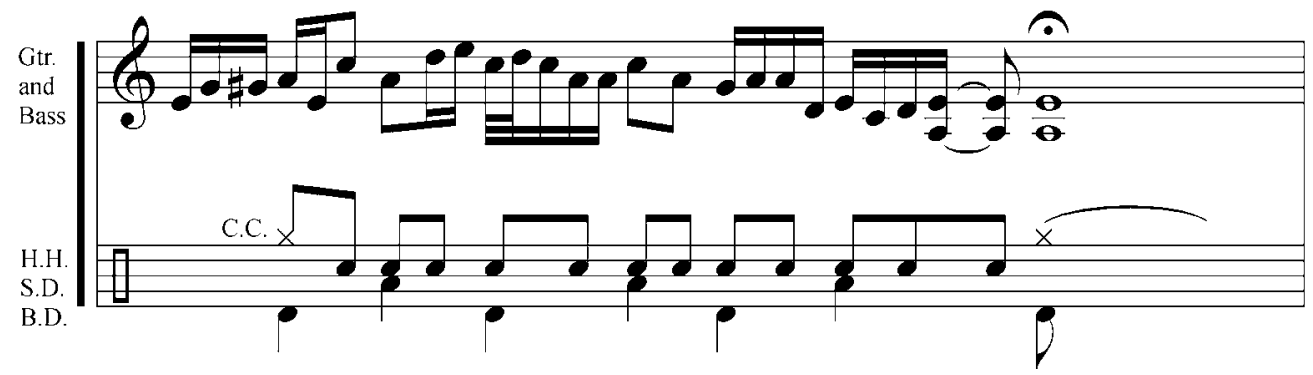

Example 11. 'Black Dog' (outtakes) - early version of riff structure.

In Example 10, I have isolated the riff to 'Black Dog' and the accompanying drumset part from any surrounding music in order to show more clearly the riff's melodic and rhythmic structure. One of the first things we may notice about the riff is its irregular length (see also Fast 2001, pp. 122-3). ${ }^{10}$ As I have notated it in Example 10, the riff spans seven quarter-notes plus a sixteenth-note (not counting the held note at the end). In this regard, the riff to 'Black Dog' is far removed from the more regular riffs heard in so many of Led Zeppelin's songs - songs such as 'Whole Lotta Love' or 'Livin' Lovin' Maid'. In addition to its irregular length, certain melodic and rhythmic features of the riff stand out. The riff begins with an anacrusis whose goal is not entirely clear. In other words, we're not sure where the pick-up puts down. Immediately following the opening group of five sixteenth-notes in the guitars and the snare drum, the change of texture initiated by John Bonham's big cymbal crash can be heard as a strong arrival point, possibly a downbeat. The number 1 in parentheses in Example 10 represents this hearing. Another way of hearing the opening is to interpret the first three sixteenth-notes of the riff as an anacrusis whose strong beat goal is the fourth sixteenth-note, the tonic pitch A (resembling the opening anacrusis figure of Fleetwood Mac's riff). In the opening to Led Zeppelin's riff, the strong beat is elided as the stark textural change discussed in the first hearing is now heard as an after-beat. The number 2 in the same example represents this second hearing.

Studio outtakes of the band rehearsing 'Black Dog' show a transformation in the way the band heard and subsequently performed the riff. ${ }^{11}$ As seen in Example 11, a transcription from these outtakes, Bonham plays a cymbal crash on the fourth sixteenth-note of the riff in a way that corresponds to the second hearing detailed in Example 10 now with the crash cymbal shifted to the left. At other spots in the rehearsal outtakes, Bonham and the rest of the band - seemingly more comfortable 
with the riff - begin to experiment with the placement of this cymbal crash. At first, the riff is played like Example 11 but, in the riff forms that follow, the crash is shifted by an eighth-note and played on the after-beat as heard in the studio version.

In the absence of a larger musical context, all of this talk about how to hear the opening of the riff might appear overly pedantic. When the riff is put back within the context of the entire song, however, things get a bit more interesting. As shown in Example 12, the unaccompanied vocal part preceding the riff establishes a regular sense of metre with its clear beginning, repetition of rhythmic motives, and Plant's emphatic delivery of the word 'Make' of 'Make you sweat' sung to his highest pitch on the downbeat of measure 2. If we continue to hear within the quadruple metre set up by the opening vocal part, the onset of the ensuing riff occurs as a sixteenth-note pickup to beat 2 of measure 3 . Because of this particular metric positioning, the riff concludes on an expected downbeat - the downbeat to measure 5 . As a result, the internal metric irregularity of the riff seems, for the moment, to have been regularised.

The call and response pattern between Plant's vocal part and the riff is heard again beginning in measure 5 . This time, however, the riff enters as a sixteenth-note pickup to measure 7. Here, if we try to hear the end of the riff as corresponding to a downbeat (a downbeat accentuated by the cymbal crash, arrival on tonic, and the onset of Plant's next vocal entry), we would be required to adjust our established sense of metre. The $3 / 4$ signature of measure 8 of Example 12 reflects this adjustment. During the course of the song, the riff appears at yet a third metric position - as a sixteenth-note immediately following the final note of Plant's vocal line. In order to see more clearly these three riff forms, Example 13 represents an abstracted version of the last measure of Plant's vocal part (shown on the top staff) and the three different metric starting points of the riff heard in the studio version of 'Black Dog'. The times included above the lower three staves indicate where each version of the riff can be heard in the studio version. Because of the irregular length of the riff itself, only the metric form of Riff A - heard only once in the song - fits with the quadruple metre established by Robert Plant's vocal part. Riffs B and C both force us to step outside of this established metric framework.

As we can see from this last example, except for its first appearance at 00:13, the riff does not enter into the regularity set up by Plant's vocal part but, instead, intrudes upon and disrupts any sense of a regular metre. As a result, the various metric placements of the riff give the studio version a looser, more improvised feel. A strong sense of metre is established during the solo vocal parts but, with the onset of the riff, we suspend any sense of metric regularity, allowing the music to float above or outside any metric interpretation. ${ }^{12}$ While we might sense some sort of metric suspension in this song, it is clear from listening to studio outtakes that a strict conception of the song's metric and rhythmic structures were clearly planned out in the studio. For example, in an outtake from the Physical Graffiti sessions, we get a glimpse of the band rehearsing 'In My Time of Dying'. At one point, Plant sings the unaccompanied line 'Jesus is gonna make up my dying bed' after which the entire band is supposed to enter. After a few brief drum hits from Bonham, the following exchange occurs between the drummer and Plant:

Bonham: We have to have a count. Because Robert there you have freedom. And then it doesn't matter what [unintelligible] we still can do it if we have a count.

Plant: Well where are you counting from now? 

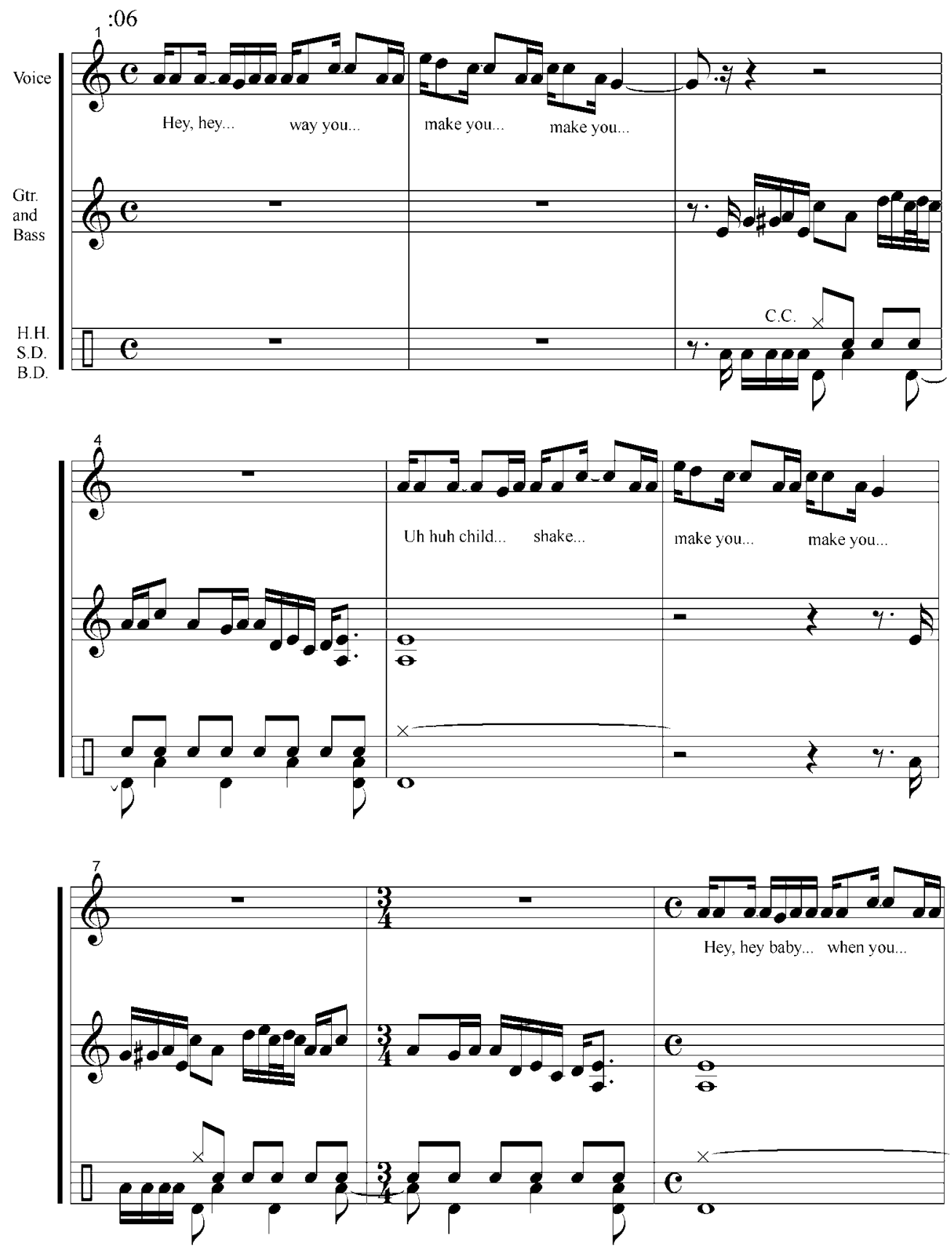

Example 12. 'Black Dog' (studio version) - opening.

Bonham: Well you can't count from where you stop 'cause your vocals might be a different - I mean - your voice just might go off a beat and we're gonna be fucked ...

Plant: Ah, but if you do that, it'll be like 'Black Dog' then it gives me room to move and solo... Bonham: Yes, but the reason we did 'Black Dog' is because we counted it and you did it afterwards ... That's the only way we can do this ... 


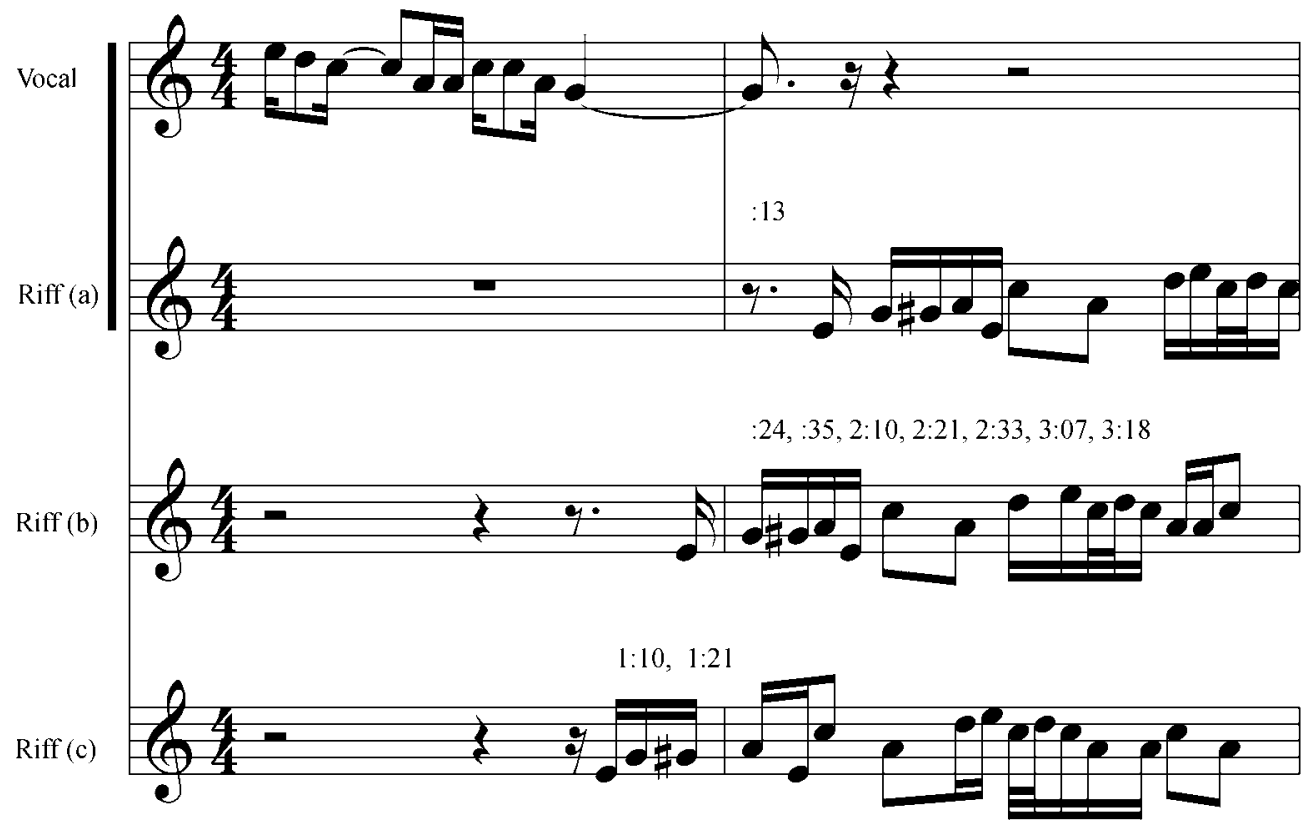

Example 13. 'Black Dog' (studio version) - various metric positions of the riff.

When recording 'Black Dog', it seems that the band carefully counted out the spaces between various entrances of the riff. After the band settled on an acceptable take, Plant came in and overdubbed his vocals, fitting his vocals to these spaces giving the impression of complete freedom and spontaneity. As this exchange seems to imply, the exact opposite appears to be the case. ${ }^{13}$

Interestingly, many of the band's live performances of 'Black Dog' are stricter, tighter, and seemingly more calculated in their placement of the riff. ${ }^{14}$ In fact, in all of the live performances of this song I have heard, the riff commences in the same metric position: immediately following the last note of Plant's vocal line (corresponding to Riff $C$ from Example 13). In these live performances it is possible to establish a certain type of metric regularity due to the fact that we know when and where the riff begins and, knowing the length of the riff, where it will conclude with the return of the vocal part. At the same time, however, we are forced to abandon a regular quadruple metric pattern. ${ }^{15}$

The metric consistency that can be heard in live performances of the riff to 'Black Dog' more closely resembles the clear-cut and predictable metric design of the original model, the riff to Fleetwood Mac's 'Oh Well'. As I have tried to show in my analysis, the unique qualities associated with the studio version of 'Black Dog' derive, in part, from the band's desire to develop certain potentialities inherent in Fleetwood Mac's original riff. Instead of the obvious metric regularity established in Fleetwood Mac's riff, the unaccompanied vocal parts and the riff to 'Black Dog' are treated almost as separate ideas, as the riff seems to intrude upon and disrupt the overall pacing implied by the call and response formal design. This gives Led Zeppelin's version a distinctive sense of hesitancy and expectation as we are not always sure when the 'boom' of the riff will be dropped. Furthermore, the 'boom' of the riff itself - the strong downbeat arrival - is obscured in Led Zeppelin's version where the guitar and drum 

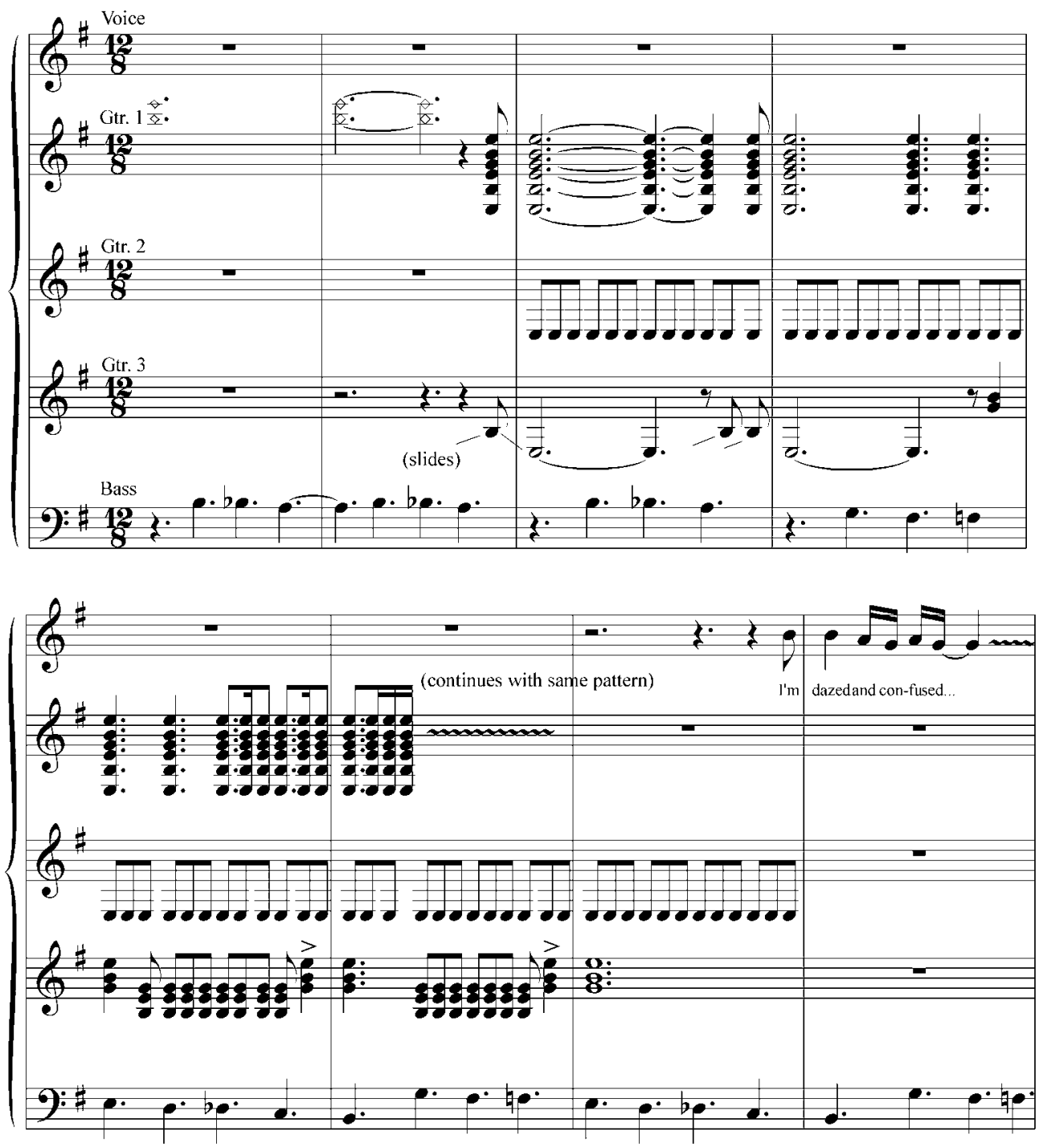

Example 14. Opening of 'Dazed and Confused' (Jake Holmes).

parts seem to reach their expected downbeat goals at different times. A similar feature is present in Fleetwood Mac's original riff where it appears at the close (see the syncopated and interlocking guitar parts leading to the held harmony near the end of Example 9). By extracting and re-positioning a similar melodic/metric fragment, Led Zeppelin were able to add to the overall sense of imbalance that has come to be associated with the studio version of 'Black Dog'.

\section{'Dazed and Confused'}

'Dazed and Confused', from the band's debut album, is a cover of a song by American folk/psychedelic singer Jake Holmes. ${ }^{16}$ Example 14 presents a partial transcription of 


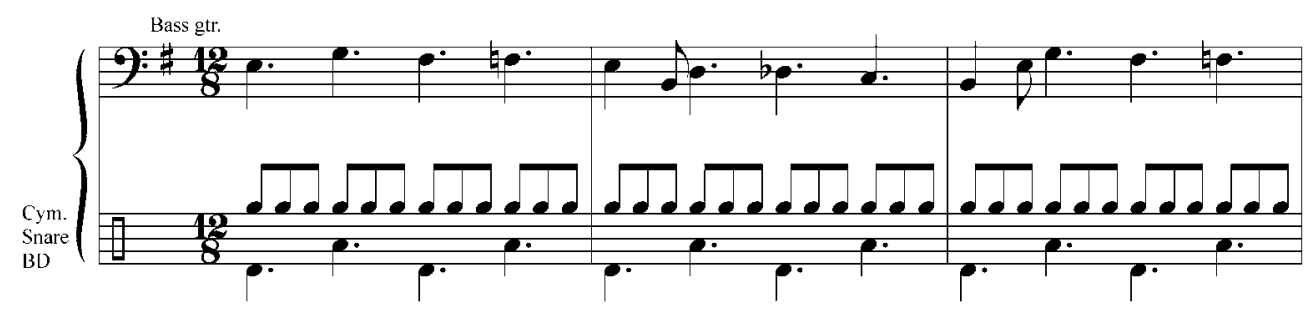

Example 15. Reduced representation of 'Dazed and Confused' (The Yardbirds).

the opening of Holmes' version up to the vocal entry. Holmes' version utilises at least three guitars and bass guitar. The guitar harmonics set the song in motion followed by the distinctive chromatic descent in the bass guitar part that also establishes the basic pulse. The repetition of the harmonics in measure 2 helps us to hear a downbeat despite the tied note in the bass. The metre is established in measures 2 to 3 with the strong anacrusis-downbeat figures in the guitars in systems 2 and 5.

Sometime after 1967, The Yardbirds covered Holmes' song during Jimmy Page's tenure as lead guitarist. In Example 15, I have provided a generic representation of how the Yardbirds transformed the original. The bass guitar picks up on measure 4 and follows Holmes' original version, treating this idea as an ostinato or, in this case, a riff. The drums serve to emphasise the metric structure present in Holmes' original version. ${ }^{17}$

In Led Zeppelin's version of 'Dazed and Confused', the riff resembles the more 'normalised' Yardbirds' version. As shown in Example 16, the entire riff occupies two $12 / 8$ measures and is formed by the two chromatic descents found in Holmes' original: a descent from $G$ down to $E$ in the first measure, the other from $D$ down to $B$ in the second measure. A strong sense of metre is established by the agogic accents at the beginning of each measure of the riff. In measure 1, the anacrusis eighth-note $E$ is followed by a wide upward leap of a tenth to the long note $G$, while in measure 2 this same figure is succeeded by an upward leap of a seventh to D. Already, this transforms the metric structure of Holmes' original and the Yardbirds' cover where these pitches and the ideas they initiate appear on beat 2. It seems that when the song made its way to Led Zeppelin, the band heard a different metric structure for the riff, different from both Holmes' original and the Yardbirds' cover.

Imitating the opening of the riff, Robert Plant's vocal entrance also begins with an eighth-note pick-up. Instead of arriving on an implied downbeat - as heard in Holmes' original and the Yardbirds' cover - Plant's vocal line begins as a pickup to beat 4 of measure 2. Plant's delivery of the second line of verse 1 (measure 4 ) falls directly on a downbeat thereby counteracting any initial sense of ambiguity. A short sixteenth-note delay signals the onset of the third line (measure 5) and any remaining sense of metric uncertainty is cleared away with the strong downbeat arrival of the fourth line of the verse (measure 6). Here, Plant emphatically leans into the downbeat, accompanying the word 'Soul' with a relatively long rhythmic value while slightly varying his vocal timbre.

The first verse is followed by two repetitions of the riff played by the entire rhythm section with Bonham playing a standard back-beat pattern. Following a second verse, the first contrasting material enters. This contrasting idea is distinguished by new melodic material, an emphasis on the minor dominant harmony, and a precise and determined rhythmic drive where a persistent and 

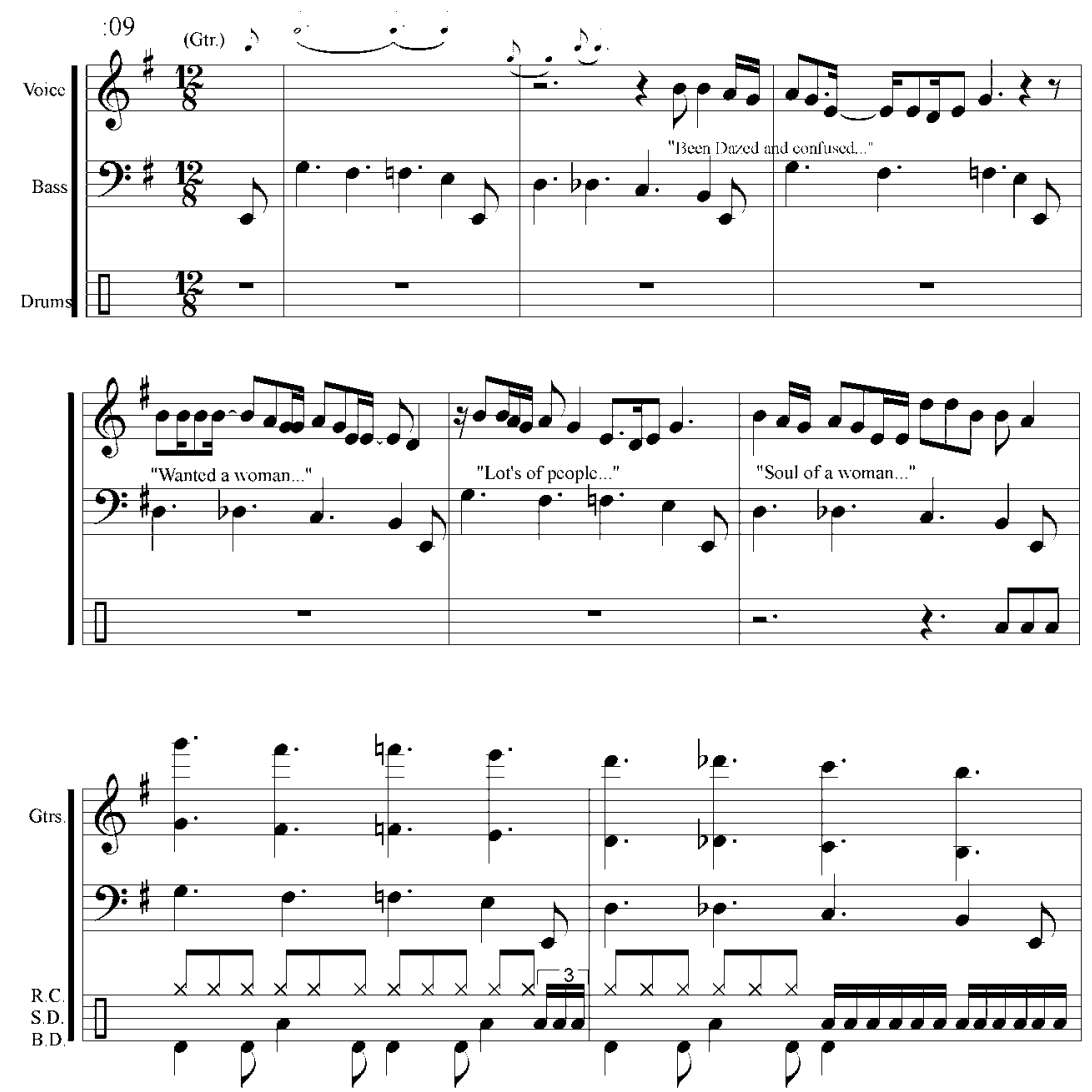

Example 16. 'Dazed and Confused' (Led Zeppelin, studio version) - opening.

regular eighth-note feel replaces the rolling and spacious dotted quarter-notes heard in the main riff. According to the metric hearing that we have established since the song's opening, the onset of this contrasting section appears to overlap with the last measure of the second verse. The pitch B of beat 4 of the second measure of the riff is also the beginning of the contrasting section. We can hear this moment in a couple of different ways. As shown in Example 17, the contrasting section can be heard as beginning on a downbeat where the last measure of the second verse is shortened by a dotted quarter-note. Another way to hear this moment involves retaining the $12 / 8$ metre established in the verse and hearing the contrasting section as beginning on large-beat 4, shown in Example 18. As the music of the contrasting section unfolds, it appears that this second way of hearing is preferable. Following four repetitions of the melodic motive associated with the contrasting section, a big arrival on a low $\mathrm{E}$ (circled in Examples 17 and 18) signals the return of the song's primary riff. For the most part, this point of arrival in measure 3 of Example 18 re-establishes the metric, rhythmic and melodic organisation of the riff as heard in the opening. Although our sense of metric regularity may have been disrupted with the onset of this contrasting music, the return of the primary riff following this moment affirms our original metric interpretation.

I say for the most part because Bonham's drum part - following the contrasting section - shifts by a full beat in relation to the established metric/melodic structure of 

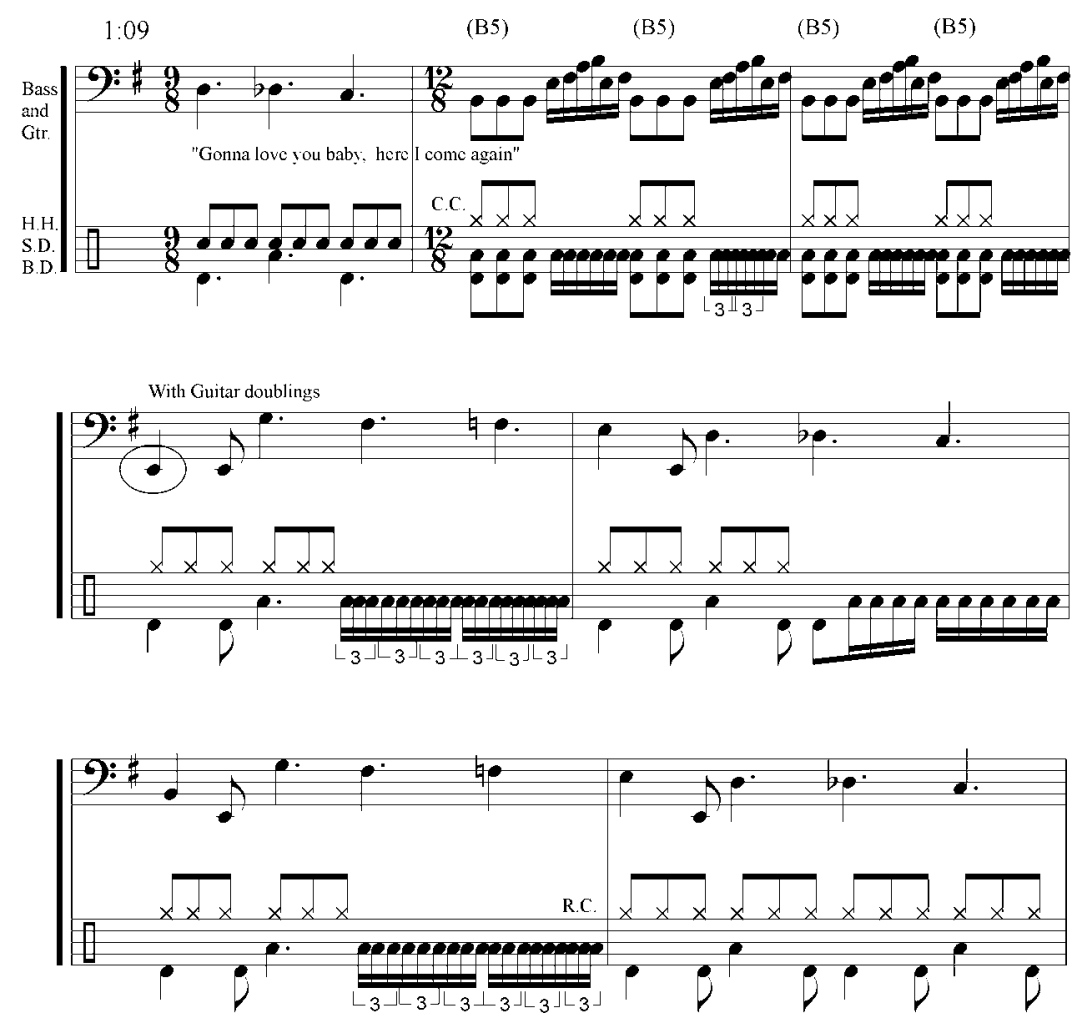

Example 17. 'Dazed and Confused' (studio version) - first hearing of transition to contrasting section and return to riff.

the riff. That is, instead of emphasising beats 2 and 4 on the snare drum as he did in the opening two verses, Bonham now plays on beats 1 and 3 . If we follow the metric interpretation provided in Example 17, the example that explains away the formal overlap, we are able to keep Bonham's backbeat pattern on beats 2 and 4 but we give up the established metric/melodic structure of the riff. No matter how we choose to hear this moment, we cannot deny that there exists a mis-alignment between the riff and the drum part following the arrival of the low E. It appears that Bonham may have heard this arrival in a way that corresponds to Example 17 (and Holmes' original version and the Yardbirds' cover) while the rest of the band heard it along the lines of Example 18. Whatever the reason, this mis-alignment persists throughout the remainder of the song as it appears on the studio album. Because the parts never line up again, we are forced to revise our metric understanding of the song according to the newly reinterpreted regularities between the melodic instruments and the drums.

'Dazed and Confused' was a staple of Zeppelin's live show. Although no two performances of the song were ever exact, the song did undergo an important transformation. With the release of BBC Sessions in 1997, three concert performances by the band from 1969 and 1971 were made commercially available for the first time. 'Dazed and Confused' was performed on two of these concerts, one from John Peel's Top Gear from June of 1969 and the other from John Peels' Rock Hour from April of 1971. The 1969 version follows the studio version almost exactly, right down to the metric/melodic shift. The later version, however, does away with the shift. In this 

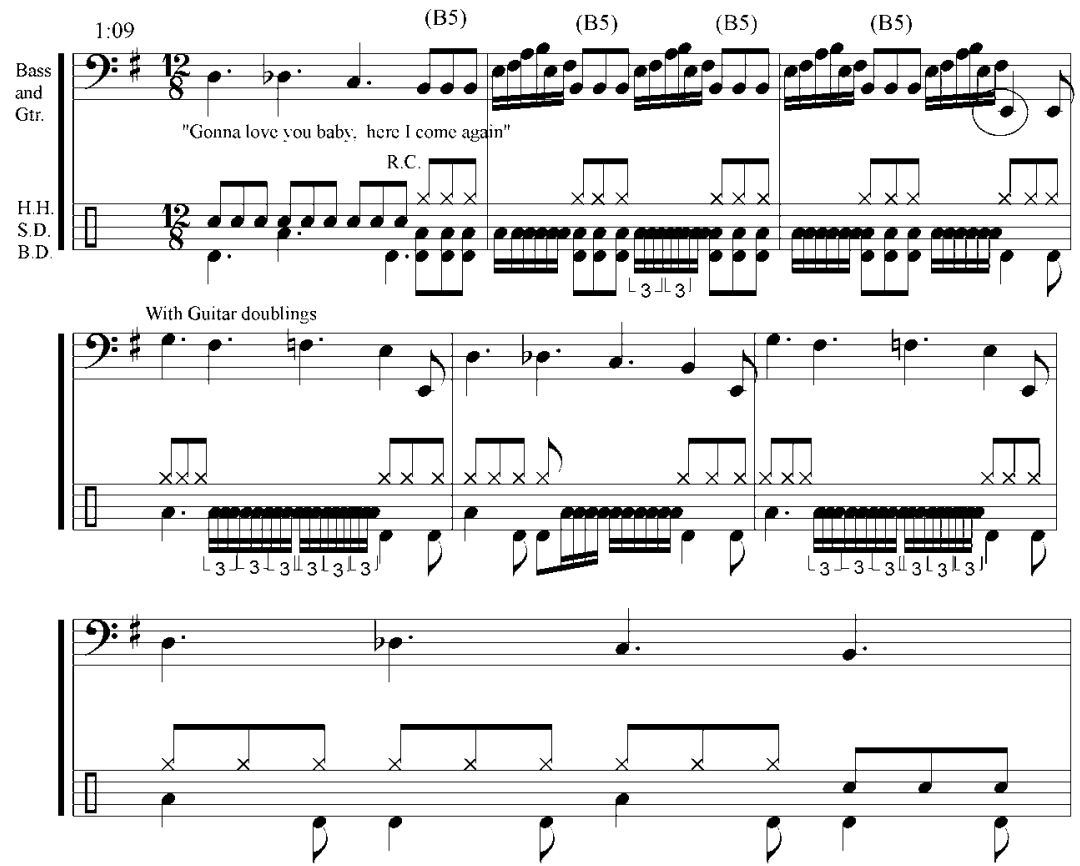

Example 18. 'Dazed and Confused' (studio version) - second hearing of transition to contrasting section and return to riff.

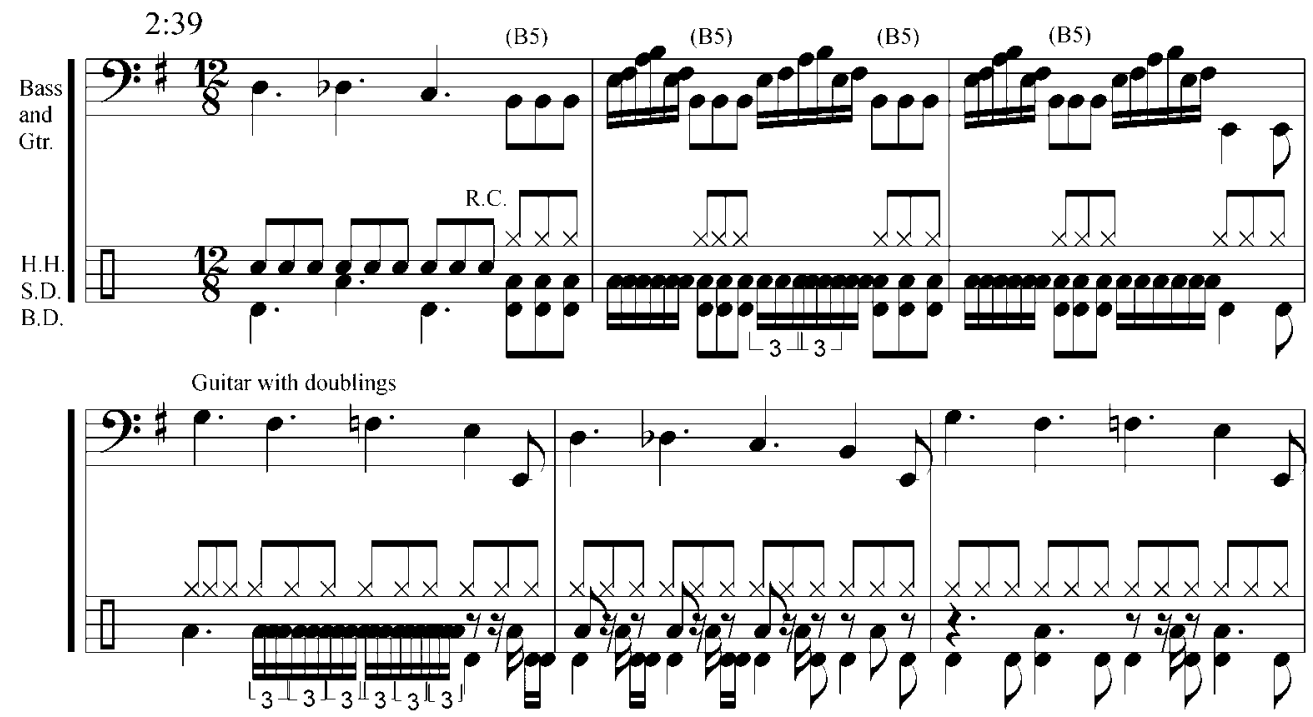

Example 19. 'Dazed and Confused' (Live/1971) - transition to contrasting section and return to riff.

performance, Bonham plays a heavily syncopated pattern following the contrasting section that disrupts any sense of metric regularity. As I have tried to show in Example 19, Bonham emerges from this rhythmic chaos emphasising the original metric/melodic structure of the riff. The shift is gone. In fact, it appears to be gone for 
good. In all of the live versions of 'Dazed and Confused' that I have been able to listen to from recordings after 1971, the metric/melodic shift never appears again. ${ }^{18}$

The metric-melodic shift that occurs in 'Dazed and Confused' is born from the inherent metric ambiguities present in Jake Holmes' original version. By the time Led Zeppelin recorded and performed this song, it had already passed through one other cover version, the version by the Yardbirds. In one sense, Led Zeppelin's version can be considered a 'cover of a cover' as certain metric and riff alignments present in the Yardbirds' version make their way into Zeppelin's. At the same time, however, Led Zeppelin transforms the fundamental riff/metric alignments over the course of the song in ways that seem to have as much to do with Holmes' original as they do with the Yardbirds' version. As a result, we are unable to clearly identify what has moved or changed: has the metric position of the riff shifted or has the backbeat been inverted? 'Dazed and Confused' indeed.

\section{Conclusion}

Led Zeppelin's ability to transform pre-existing genres (funk as seen in 'The Crunge'), riffs or formal models ('Black Dog'), and songs ('Dazed and Confused') through their unique approach to rhythm and metre is - along with other musical parameters such as timbre and instrumentation - an important component of the band's individual style. The various rhythmic and metric tendencies employed by the band function as key musical-stylistic 'stamps' signifying Led Zeppelin's style that are instantly identifiable even as they borrow or develop earlier musical genres, models or songs. From a theoretical perspective that considers the notion of style in various forms of popular music, identifying markers such as those described in my analyses might function as concrete indicators that distinguish one band from another, bands that might typically be understood as stylistically similar. From a different perspective, one that focuses on 'originality' or 'authorship', such features can serve a variety of functions, a notable function being the ability to identify or locate what is 'new' or 'original' in a song that might otherwise be considered a cover version or a borrowing.

It is this second perspective that is the primary focus of Headlam (1995). Set against the backdrop of Willie Dixon's lawsuit over the band's cover of Dixon's 'You Need Love' (re-worked by Led Zeppelin as 'Whole Lotta Love') and other lawsuits brought against the band concerning the unattributed use of copyrighted material, Headlam analyses a number of Led Zeppelin covers and re-workings in an attempt to not only problematise the question of authorship in the world of rock and pop music, but also to lay bare some of the stylistic features that are uniquely associated with Led Zeppelin. ${ }^{19}$ In his comparative analyses, Headlam describes a number of significant alterations (thematic and motivic, harmonic, as well as rhythmic) that distinguish Led Zeppelin's covers or re-workings from the original songs. Headlam ultimately concludes that 'the question of whether Led Zeppelin can be considered the true "authors" of their own music cannot be determined by copyright laws or attitudes toward proven or unproven influences or appropriation. The true evidence lies in the music itself, independently of the social and cultural concerns of popular music writers, and can only be discovered by analysis of the musical features themselves' (Headlam 1995, p. 362).

As I have tried to show, key 'musical features' of Led Zeppelin's style might include certain rhythmic and metric tendencies, from mobile rhythmic units or entire riffs to ambiguous downbeats or 'inverted backbeats'. At the same time, however, we 
must avoid the tendency to identify these (and other) 'musical features' as being specific only to Led Zeppelin's musical practices. Without a doubt, the rhythmic and metric techniques described in my analyses are not sui generis, springing from the creative facilities of Led Zeppelin. Many examples can be cited of songs that evince similar rhythmic or metric tendencies, songs that would have been familiar to the members of Led Zeppelin. For example, Headlam identifies an interesting melodicmetric shift in Muddy Water's 'You Need Love', a shift that clearly resembles what occurs in 'Dazed and Confused' (Headlam 1995, pp. 332-43). Cream's cover of Howlin' Wolf's 'Sitting On Top of the World' employs a very interesting start and stop rhythmic pattern that works quite strongly against the prevailing compound duple metre in a way that is reminiscent of what is heard in 'Black Dog'. In another example from Cream, 'Politician', drummer Ginger Baker sounds like he wants to play a waltz pattern over the $4 / 4$ blues groove played by the rest of the band. This sense of stratified metric layers is perceptible not only in 'Black Dog' but also 'Kashmir' as well. Furthermore, the 'irregular regularity' of 'The Crunge' can be linked to the numerous phrase extensions or contractions often encountered in early blues performances.

The picture that emerges, then, is that even those rhythmic and metric techniques described in my analyses are, themselves, traceable to earlier genres, models, and/or specific songs. Such a fact could be used as further evidence supporting the charge that Led Zeppelin are 'musical pilferers' (Guterman 1991, p. 41) and that their music cannot be considered 'original' because they rely so heavily on the ideas of other artists.

Such an argument, I believe, misses certain key points pertaining to the complex relationships between influence and originality in discussions of a band's style. We must remember that the lawsuits brought against Led Zeppelin focused primarily on the band's unattributed use of lyrical material. Given our modern-day copyright laws, it is clear that Led Zeppelin was in the wrong, despite any appeals to contemporary practices (many other bands freely borrowed lyrics from earlier sources) or audience expectations. (Dave Headlam correctly points out that Led Zeppelin 'developed at a time when "cover" bands were greatly appreciated, and American audiences cheered groups like the Rolling Stones and Cream as they performed songs originally written by [earlier musicians]' [Headlam 1995, p. 362].) When we turn our attention from lyrics to specific musical features such as riffs or certain rhythmic/metric strategies, it is not clear if claims pertaining to ownership or authorship apply in either a legal sense (copyright) or in an evaluative sense (originality). Robert Palmer makes his position clear: 'You can copyright a melody or lyrics, but not styles or riffs or rhythm patterns' (Palmer 1990, [n.p.]).

While we might be able to find predecessors to the types of rhythmic and metric processes described in my analyses, we must - I believe - understand them from the perspective of influence. More specifically, we must allow for the possibility that an individual or band adopted certain musical practices or musical strategies learned from (hence influenced by) earlier artists, styles or genres. A band's originality, or sense of individual style, subsequently develops from its ability to combine and transform these and other musical influences - harmonic progressions, rhythmic ideas, approaches to instrumentation, etc. - in novel ways. The complex interactions between a variety of musical features and musical styles work together in forming an individual style. Therefore, the analytical observations presented above should be understood as representing only one aspect of a much larger project that is required 
when attempting to describe a notion as slippery and complex as style. To accurately represent and describe Led Zeppelin's individual style, the types of rhythmic and metric practices detailed in this essay (as well as those that appear in Headlam 1995, Fast 2001 and Moore 1993, among many others) must also take into account a number of other sonic features, most notably certain timbral characteristics associated with the band's recording and engineering practices. For reasons of space and scope (not to mention my woeful lack of knowledge in matters relating to recording and production techniques), I have chosen to focus on only one aspect of Led Zeppelin's musical practices. Hopefully, future work in the area of popular music style(s) will develop a methodology that effectively combines the 'musical features themselves' (i.e. rhythmic, melodic, and/or harmonic regularities) with aspects of sound production and sound recording, for it is only when all of these factors and issues are taken into account that the notion of a distinctive style can even begin to make sense. $^{20}$

\section{Acknowledgements}

I would like to thank John Covach, Dave Headlam, Andy Flory, and the anonymous reviewers at Popular Music for their helpful comments and criticisms. I would also like to thank Jennifer Chartier at Hal Leonard Corporation for allowing me to reproduce excerpts from Jake Holmes' 'Dazed and Confused'. Every attempt was made to secure permissions from Alfred Publishing for the Led Zeppelin, James Brown and Fleetwood Mac examples.

\section{Copyright acknowledgements}

'Dazed and Confused', Words and Music by Jake Holmes. Copyright (c) 1967 Universal Music Corp. Copyright Renewed. All Rights Reserved. Used by Permission.

\section{Endnotes}

1. Interview included on the bootleg recording Conversations With Led Zeppelin (disc 1, track 1: 20:35-21:38). No definitive information on the locations and dates of these interviews is provided. The interview with Plant and Bonham from which the excerpted quote appears might have occurred sometime in 1972. Plant mentions the release of Led Zeppelin IV (released in 1971) and concerts in Australia, concerts that took place in February of 1972.

2. The opening riff is not entirely unaccompanied: a brief clavinet part appears during the second repetition while an overdubbed guitar part is present in the third and fourth repetitions. Neither of these parts, however, helps to clarify any type of metric regularity.

3. To be sure, it is possible that no sense of metric ambiguity is perceived in the song's opening. If we hear a quicker pulse (for example, if we understand the sixteenth-note values in Examples $2 \mathrm{a}$ and $2 \mathrm{~b}$ as eighth-notes) then any anacrusis/downbeat ambiguity seems to evaporate. However, the ensuing drum part must then be understood in 'half-time'. In fact, we will be forced to view the drums as playing in half-time throughout the entire song. My transcription reflects the fact that I privilege a standard backbeat pattern with the snare drum on beats 2 and 4 .

4. For the purposes of this essay, I will be employing the term 'groove' as referring to the interlocking rhythmic and metric patterns formed by the entire ensemble. This roughly follows the definition given in Spicer (2001): 'Groove: the complex tapestry of riffs - usually played by the drums, bass, rhythm guitar and/or keyboard in some combination - that work together to create the distinctive harmonic/rhythmic backdrop which identifies a song' (Spicer 2001, p. 10). While I am not in complete agreement with this definition, it is sufficient for the purposes of the present paper. 
5. Brackett (1995) and Wilson (1974) consistently refer to the polymetric profiles of the individual lines in Brown's 'Superbad'. I don't hear polymetre so much as I hear different rhythmic patterns that all serve to emphasise different points within the prevailing duple metre.

6. Available on Deep Throat II. The band played a good portion of "The Crunge" a night earlier as part of 'Whole Lotta Love' (heard on Deep Throat I).

7. A few words regarding my notational decisions are in order. Although each measure of Example 4 comprises nine eighth-notes, a time signature of $9 / 8$ would not, I believe, adequately reflect my sense that each measure contains 4 nonisochronous beats. The three beat pulse of $9 / 8$ would obscure this quadruple feeling. (Incidentally, Moore 1993 describes this particular song as 'nominally in 4/4 ...' [Moore 1993, p. 72].) In reading Example 4 (and the examples that follow that also utilise similar time signature indications), it is useful to think 'two quarter-note beats PLUS a beat of three eighth-notes PLUS a quarter-note' as equalling one measure. I experimented with a variety of time signatures when transcribing the examples to "The Crunge'. Although I am not entirely satisfied with the end result, it does, I believe, best represent my hearing.

In a commercially available transcription of this song, the editors transcribe the opening measures in 5/4 (Led Zeppelin, 1973). It seems that they ran into the same difficulties I did and, rather than come up with some compromise, they had no choice but to misrepresent what actually happens in the music by adding an extra eighth note.

8. See Cross (1991, p. 129). Not coincidentally, when Jimmy Page toured with the American band The Black Crows, Fleetwood Mac's 'Oh Well' was regularly featured during live shows. See Jimmy Page and the Black Crows, Live at the Greek.

9. The larger structure of 'Oh Well' is essentially a two-part form consisting of the opening 'heavy' section followed by a 'lighter' second section. This might have appealed to the band's own formal proclivities; see, among others, 'Babe I'm Gonna Leave You', 'What Is and What Should Never Be', and, of course, 'Stairway to Heaven'. See the discussion of 'Babe I'm Gonna Leave You' in Headlam (1995, pp. 343-53).

10. Fast (2001) transcribes the song in $2 / 4$, using eighth-notes in place of the sixteenth-notes used in my transcription. My transcription decisions are based on an unreleased acetate of songs from Led Zeppelin IV, available on the bootleg recording Control Monitor Mixes. On the version of 'Black Dog' included on this recording, Bonham can clearly be heard counting off a tempo and pulse that corresponds to my $4 / 4$ transcription decisions.

11. These outtakes are included on a number of bootleg recordings. These examples come from an eleven-CD set entitled Studio Daze. The material relating to 'Black Dog' appears on CD 6, track 1.

12. This reverses a tendency described in Waterman (1952): 'Examples of call-andresponse music in which the solo part, for one reason or another, drops out for a time, indicate clearly that the chorus [response] part, rhythmical and repetitive, is the mainstay of the songs and the one really inexorable component of the rhythmic structure. The leader, receiving solid rhythmic support from the metrically accurate, rolling repetition of phrases by the chorus, is free to embroider at will' (Waterman 1952, p. 214).

13. This exchange can be heard on a number of non-commercial recordings. See, for example, Physically Present, track 3 (00:20-00:56). See also Studio Daze, Disc 9, track 9 (11:50-12:30).

14. This fact reverses what we might generally expect from live performances where the music is freer and more spontaneous in comparison to the rigidity of studio versions.

15. Readers familiar with 'Black Dog' are probably wondering why I do not consider the middle section, where the riff is transposed, fragmented and syncopated. I have two reasons: first, Fast (2001) provides an excellent discussion of this section (see especially pp. 122-3 and her Example 4.6 on pp. 126-7). Second, although complex, there is nothing really metrically ambiguous about this section. The guitars play a syncopated variation of the riff against Bonham's backbeat drum part. What is interesting about this section is how the pesky crash cymbal gets transferred to the downbeat when the riff returns to tonic.

16. See Fast (2001, chap. 1) for an extended discussion of this song.

17. The Yardbirds' version expands upon and develops the psychedelic middle section of Holmes' version. Many of the formal features and a great many musical ideas first used in the Yardbirds' version make their way into Led Zeppelin's version. See Fast (2001, pp. 21 ff).

18. It is quite possible that the metric shift was done away with shortly after the 1969 recording included on the BBC Sessions release. As stated in the body of my essay, the metric shift does appear in 'Dazed and Confused' from this 1969 recording, recorded 3 March. On 21 July, the band played a show in Central Park in New York City as part of the Schaefer Music Festival where the shift is not used. At some point between these two dates, the shift was abandoned. The 21 July show is available on a number of bootleg releases, including Central Park 1969, Complete Central Park, Schaefer Music Festival, Superstars and Twist.

19. Headlam (1995) makes the distinction between 'covers' and 're-workings'. See also Shaw (1974, pp. 124-6).

20. Some of this work is already starting to be done. See, for example, Zak (2001) and Everett (1999 and 2001). 


\section{References}

Brackett, D. 1995. Interpreting Popular Music (Cambridge, Cambridge University Press)

Carson, P. 2004. 'The Rover', The Greatest Classic Rock Albums Ever! Q/Mojo, Special Limited Edition, Fall, pp. 13-14

Cross, C. 1991. 'Tales from Led Zeppelin's recording sessions', in Led Zeppelin: Heaven and Hell, ed. C.R. Cross and E. Flannigan (New York, Harmony Books), pp. 107-56

Everett, W. 1999. The Beatles as Musicians: Revolver through the Anthology (Oxford, Oxford University Press)

2001. The Beatles as Musicians: The Quarry Men through Rubber Soul (Oxford, Oxford University Press)

Fast, S. 2001. In the Houses of the Holy: Led Zeppelin and the Power of Rock Music (Oxford, Oxford University Press)

Goodwin, A., and Gore, J. 1987. 'Your time is gonna come: talking about Led Zeppelin', OneTwoThreeFour: A Rock ' $n$ ' Roll Quarterly, 4 (Winter), pp. 4-11

Guterman, J. 1991. 'Your time is gonna come: the blues and other inspirations', in Led Zeppelin: Heaven and Hell, ed. C.R. Cross and E. Flannigan (New York, Harmony Books), pp. 37-44

Headlam, D. 1995. 'Does the song remain the same?: Questions of authorship and identification in the music of Led Zeppelin', in Concert Music, Rock, and Jazz Since 1945, ed. E. West Marvin and R. Hermann (Rochester, University of Rochester Press), pp. 313-63

1997. 'Blues transformations in the music of Cream', in Understanding Rock: Essays in Musical Analysis, ed. J. Covach and G. Boone (New York, Oxford University Press), pp. 59-92

Kendall, P., and Lewis, D. 1995. Led Zeppelin: In Their Own Words (London, Omnibus Press)

Led Zeppelin. 1973. Led Zeppelin: Houses of the Holy (New York, Superhype Publishing)

Moore, A.F. 1993. Rock: The Primary Text (Buckingham, Open University Press)

Palmer, R. 1990. 'Led Zeppelin: The Music', liner notes accompanying Led Zeppelin, Atlantic 82144-2, no page numbers

Shaw, A. 1974. The Rockin' '50s. (New York, Hawthorn Nooks)

Spicer, M. 2001. British Pop-Rock Music in the Post-Beatles Era: Three Analytical Studies, Ph.D. diss., Yale University

Waterman, R.A. 1952. 'African influence on the music of the Americas', in Acculturation in the Americas, ed. S. Tax (Chicago, University of Chicago Press), pp. 207-17

Welch, C. 1999. Led Zeppelin: Dazed and Confused (New York, Thunder's Mouth Press)

Wilson, O. 1974. 'The significance of the relationship between Afro-American music and West African music', The Black Perspective in Music, 2 (Spring), pp. 3-22

Zak, A. 2001. The Poetics of Rock (Berkeley, University of California Press)

\section{Discography}

\section{Commercial Releases}

Fleetwood Mac, Then Play On. Reprise 6368-2. 1970

Jake Holmes, The Above Ground Sound of Jake Holmes. Tower T5079. 1967

Jimmy Page and the Black Crows, Live at the Greek. TVT 2140-2. 2000.

Led Zeppelin, Led Zeppelin. Atlantic SD 19126-2. 1994; originally released as Atlantic 19126. 1969

Led Zeppelin IV. Atlantic 82638-2. 1994; originally released as Atlantic 19129. 1971

Houses of the Holy. Atlantic A2-19130. 1994; originally released as Atlantic 19130. 1973

Physical Graffiti. Swan Song 92442-2. 1994; originally released as Swan Song 2-200. 1975

Led Zeppelin. Atlantic 821444-2. 1990

BBC Sessions. Atlantic 83061-2. 1997

The Yardbirds, Cumular Limit. Burning Airlines, Pilot 24 800945000246. 2000

\section{Unreleased material}

Led Zeppelin, Control Monitor Mixes. Watchtower WT-20020895. No date

Studio Daze. No label. No date

Deep Throat I. Empress Valley Supreme Disc. 2003

Deep Throat II. Empress Valley Supreme Disc. 2003

Conversations With Led Zeppelin. No label. No date

Physically Present. House of Elrond. No date 